\title{
Solution-phase automated synthesis of an $\alpha$-amino aldehyde as a versatile intermediate
}

\author{
Hisashi Masui ${ }^{1}$, Sae Yosugi ${ }^{1}$, Shinichiro Fuse ${ }^{2}$ and Takashi Takahashi ${ }^{* 1}$
}

\author{
Letter \\ Address: \\ ${ }^{1}$ Yokohama University of Pharmacy, 601 Matano-cho, Totsuka-ku, \\ Yokohama 245-0066, Japan, and ${ }^{2}$ Laboratory for Chemistry and Life \\ Science, Institute of Innovative Research, Tokyo Institute of \\ Technology, 4259 Nagatsuta-cho, Midori-ku, Yokohama 226-8503, \\ Japan \\ Email: \\ Takashi Takahashi" - ttak@hamayaku.ac.jp \\ * Corresponding author \\ Keywords: \\ acetal formation; amino acid; automated synthesis; Garner's \\ aldehyde; reduction
}

\begin{abstract}
A solution-phase automated synthesis of the versatile synthetic intermediate, Garner's aldehyde, was demonstrated. tert-Butoxycarbonyl (Boc) protection, acetal formation, and reduction of the ester to the corresponding aldehyde were performed utilizing our originally developed automated synthesizer, ChemKonzert. The developed procedure was also useful for the synthesis of Garner's aldehyde analogues possessing fluorenylmethyloxycarbonyl (Fmoc) or benzyloxycarbonyl (Cbz) protection.
\end{abstract}

\section{Introduction}

Automated synthesis has attracted a great deal of attention in recent years because the automation of synthetic operations improves both the reproducibility and reliability of syntheses [1-4]. Synthetic chemists frequently perform repetitive processes such as the optimization of reaction conditions, construction of compound libraries, and preparation of synthetic intermediates. These operations are very time-consuming, and do not require expert knowledge and skills. Development of automated synthetic procedures and storage of relevant digital data allow anyone to reproduce the same results anytime and anywhere using the same apparatus and reagents. As a result, synthetic chemists can spend more time on advanced and chal- lenging problems. We previously reported automated syntheses of various bioactive compounds [5-8], including taxol, using our originally developed solution-phase automated synthesizer, ChemKonzert [9].

Protected $\alpha$-amino aldehydes are versatile intermediates for the synthesis of vicinal amino alcohols and important building blocks for various bioactive natural products [10-12]. In particular, Garner's aldehyde (4a) is very useful as a chiral building block [13-18]. It is sufficiently stable and its configurational rigidity allows stereoselective addition of nucleophiles to the aldehyde [19].

\author{
Beilstein J. Org. Chem. 2017, 13, 106-110. \\ doi:10.3762/bjoc. 13.13 \\ Received: 01 October 2016 \\ Accepted: 19 December 2016 \\ Published: 17 January 2017 \\ This article is part of the Thematic Series "Automated chemical \\ synthesis". \\ Guest Editor: I. R. Baxendale \\ (C) 2017 Masui et al.; licensee Beilstein-Institut. \\ License and terms: see end of document.
}


The most conventional synthesis of $\mathbf{4 a}$ involves the protection of the amine, the carboxylic acid, and the alcohol moiety of serine, and the subsequent reduction of carboxylic acid derivatives such as ester [20-27], thioester [28], or Weinreb amide $[29,30]$ to the aldehyde. In addition, Burke and co-workers reported an asymmetric hydroformylation of 2,2-dimethyl-2,3dihydrooxazole for the synthesis of $\mathbf{4 a}$ [31]. Although various syntheses of $\mathbf{4 a}$ have been established, an automated synthesis has never been demonstrated. The automated synthesis of a versatile intermediate such as $\mathbf{4 a}$ will improve the overall research efficiency of synthetic chemists. Herein, we report the first solution-phase automated synthesis of Garner's aldehyde (4a) and its analogues.

\section{Results and Discussion}

Our synthetic route is shown in Scheme 1. We planned to synthesize $4 \mathbf{a}$ with various protecting groups from a commercially available amino ester through a three-step procedure utilizing the automated synthesizer, ChemKonzert (Figure 1).
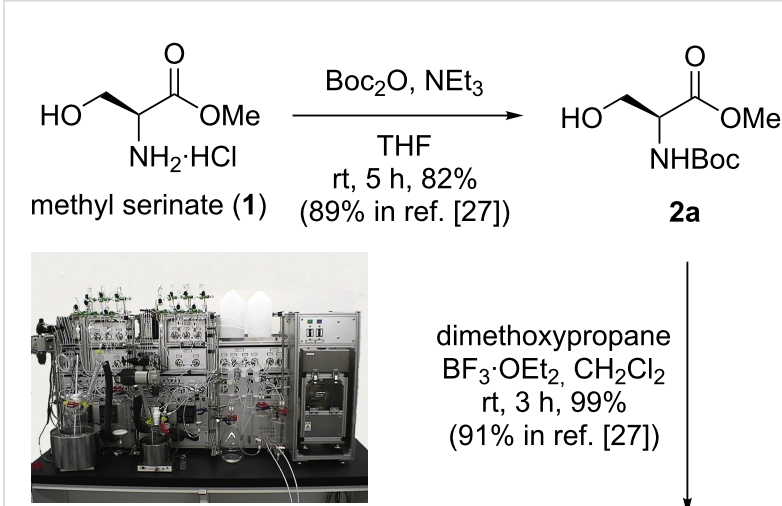

ChemKonzert
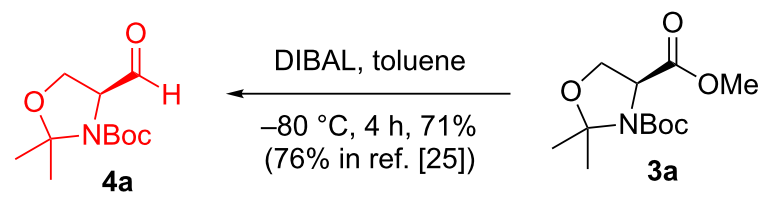

Scheme 1: Automated synthesis of $4 a$.

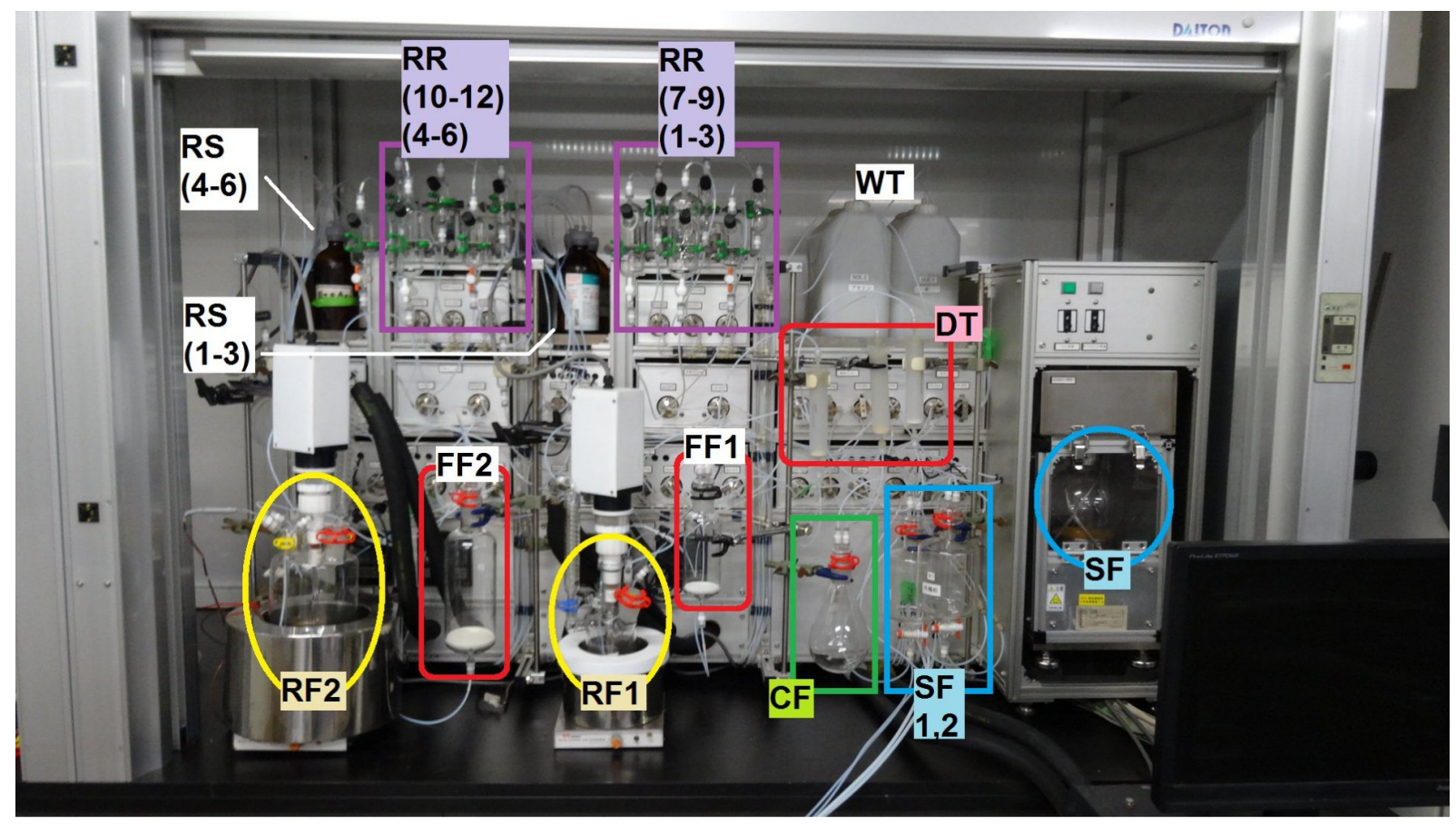

Figure 1: Full picture of ChemKonzert, showing two reaction vessels (RF1 and RF2), a centrifugal separator (SF, $700 \mathrm{~mL}$ ), two receivers (SF1 and SF2, $500 \mathrm{~mL}$ ), two glass filters (FF1 and FF2, 500 and $100 \mathrm{~mL}$ ), 12 substrate and reagent reservoirs (RR1-RR12, 100-200 mL), six solvent and wash-solution bottles (RS1-RS6, $500 \mathrm{~mL}$ ), three drying pads (DT1-DT3), a round-bottom flask (CF), two solvent tanks (WT1 and WT2), and a computer controller. Transfer of compounds from a server flask to a receiver flask through a Teflon tube is performed as shown below. The receiver flask is vacuumed by a diaphragm pump and $\mathrm{N}_{2}$ flow pushes the compound into the server flask. The flow of liquid in the tube is monitored by a photosensor that detects the difference in reflective index between gas and liquid. All the gas/liquid flows are controlled by solenoid valves and/or rotary valves. This transfer system avoids direct contacts of pumps with compounds that frequently cause mechanical troubles of pumps. Formation of emulsions during phase separation is one of the common problems for liquid-phase automated synthesizers that can perform aqueous work-up.

ChemKonzert uses a centrifuge instrument to solve this problem: the emulsified mixture is transferred to the separating flask and the phases are separated by centrifugation. The separated mixture is then transferred to a receiver flask from the lower layer by passing through a flow-type electroconductivity sensor, which detects the difference in conductivity between the organic phase and aqueous phase. When the sensor detects the boundary of the phases, the solenoid valve is changed to send the upper layer to a different receiver. 
Figure 1 shows the automated synthesizer ChemKonzert and its various components. An automated synthesis of 4a was examined utilizing ChemKonzert (Scheme 1). It is important to examine and check the reaction conditions manually before performing the automated synthesis. Therefore, we optimized the reaction time and the work-up method was modified. We started with the Boc protection of methyl L-serinate hydrochloride (1). The computer controlling the automated synthesizer was programmed with a specific procedure. The substrate, reagents, solvents, and wash solutions were added to the reaction vessel (RF1), reagent reservoir (RR1), solvent bottles (RS1-3), and wash solution bottles (RS4-6), respectively. A solution of methyl L-serinate hydrochloride in THF was stirred at $25^{\circ} \mathrm{C}$ in $\mathrm{RF} 1$, to which a solution of triethylamine in THF and $\mathrm{Boc}_{2} \mathrm{O}$ in THF was added. Originally, the respective solutions were loaded in the reagent reservoirs (RR1 and RR3). After stirring at $25{ }^{\circ} \mathrm{C}$ for $5 \mathrm{~h}$, the reaction mixture was diluted with ethyl acetate from RS1 and was quenched by adding $1 \mathrm{M} \mathrm{HCl}$ from RR2. The reaction mixture was then transferred to the centrifugal separator (SF). After centrifugation, the two resulting phases were separated; their electroconductivities measured with a sensor and transferred to two receivers (SF1 and SF2). The aqueous phase in SF1 was returned to RF1. Ethyl acetate, from RS1, was added, and the mixture was stirred for $3 \mathrm{~min}$ and then transferred to SF. After performing the extraction, the combined organic mixture in the receiver (SF2) was washed with $10 \%$ aqueous $\mathrm{NaCl}$ solution from $\mathrm{RS} 3$. The organic layer was separated in SF, transferred to SF2, subsequently passed through a plug of anhydrous $\mathrm{Na}_{2} \mathrm{SO}_{4}$ (DT1) and collected in a round-bottom flask (CF1). The collected solution was manually concentrated in vacuo. The obtained residue was purified manually using silica gel column chromatography. Carbamate 2a was obtained in $82 \%$ yield.

Acetal formation was also demonstrated using ChemKonzert. A solution of substrate $2 \mathrm{a}$ in dichloromethane was stirred at $25^{\circ} \mathrm{C}$ in the reaction vessel (RF1), to which a solution of 2,2- dimethoxypropane in dichloromethane and a solution of boron trifluoride-ethyl ether complex in dichloromethane were added. Originally, the respective solutions were loaded into the reagent reservoirs (RR1 and RR3). After stirring at $25^{\circ} \mathrm{C}$ for $3 \mathrm{~h}$, the reaction was quenched by adding $50 \%$ aqueous $\mathrm{NaOH}$ solution. When the $\mathrm{NaOH}$ solution was added to RF1, the yield of the target compound decreased because of the undesired hydrolysis of the acetonide. Therefore, the reaction mixture was transferred to the centrifugal separator ( $\mathrm{SF}$ ), $\mathrm{NaOH}$ solution was added to RF1 and the reaction mixture in SF was added to the $\mathrm{NaOH}$ solution in RF1. This reverse addition improved the yield. The subsequent automated aqueous work-up, manual concentration, and silica gel column chromatography afforded acetonide $\mathbf{3 a}$ in $99 \%$ yield.

DIBAL reduction was also achieved using ChemKonzert. The amount of Rochelle salt required to diminish the aluminum salt generated from DIBAL was optimized in manual operation preliminarily. A solution of the substrate in toluene was stirred at $-80{ }^{\circ} \mathrm{C}$ in the reaction vessel (RF1). A solution of DIBAL in toluene, originally loaded into the reagent reservoir (RR1), was added to RF1. After further stirring at $-80{ }^{\circ} \mathrm{C}$ for $4 \mathrm{~h}$, the reaction was quenched by adding saturated aqueous Rochelle salt solution at $25{ }^{\circ} \mathrm{C}$ from the solvent bottle RS2. The subsequent automated aqueous work-up, manual concentration, and silica gel column chromatography afforded $\mathbf{4 a}$ in $71 \%$ yield. The observed yields of the automated syntheses were similar to those obtained from the corresponding reported manual syntheses (see Scheme 1).

Garner's aldehyde analogues containing a Fmoc [32] or Cbz [33-35] group were synthesized using the established procedure. Protection of the amino group in methyl serinate using Fmoc- $\mathrm{OSu}$ or $\mathrm{CbzCl}$ afforded the corresponding carbamates in good yields (Table 1, experimental details, see Supporting Information File 1). Acetal formation and reduction were performed by the developed procedure in ChemKonzert (Table 1).

Table 1: Automated synthesis of $\mathbf{4 b}$ and $\mathbf{4 c}$.

\begin{tabular}{|c|c|c|c|c|c|c|}
\hline \multirow{3}{*}{ methyl serinate (1) } & \multirow{3}{*}{$\begin{array}{r}\stackrel{\text { conditions }}{\longrightarrow} \\
\stackrel{\text { protection }}{\longrightarrow}\end{array}$} & \multirow{3}{*}{$\begin{array}{l}\text { 2b: } \mathrm{PG}=\mathrm{Fmoc} \\
\text { 2c: } \mathrm{PG}=\mathrm{Cbz}\end{array}$} & \multirow{2}{*}{$\begin{array}{c}\text { dimethoxypropane } \\
\underset{\mathrm{BF}_{3} \cdot \mathrm{OEt}_{2}, \mathrm{CH}_{2} \mathrm{Cl}_{2}}{\mathrm{rt}, 3 \mathrm{~h}}\end{array}$} & \multirow{2}{*}{\multicolumn{2}{|c|}{$\begin{array}{l}\text { DIBAL, toluen } \\
-80^{\circ} \mathrm{C}, 4 \mathrm{~h} \\
\end{array}$}} & \multirow[b]{3}{*}{$\begin{array}{l}\text { 4b: } P G=F m o c \\
\text { 4c: } P G=C b z\end{array}$} \\
\hline & & & & & & \\
\hline & & & acetal formation & $\begin{array}{l}\text { 3b: } P G=F m o c \\
3 c: P G=C b z\end{array}$ & reduction & \\
\hline$P G$ & \multicolumn{3}{|c|}{ Protection } & \multicolumn{2}{|c|}{ Acetal formation } & Reduction \\
\hline Fmoc & \multicolumn{3}{|c|}{ Fmoc-OSu, $\mathrm{NaHCO}_{3}$, dioxane, $\mathrm{H}_{2} \mathrm{O}$, rt, $5 \mathrm{~h}, 97 \%$} & \multicolumn{2}{|l|}{$87 \%$} & $22 \%$ \\
\hline $\mathrm{Cbz}$ & \multicolumn{3}{|c|}{$\mathrm{CbzCl}, \mathrm{NaHCO}_{3}$, dioxane, $\mathrm{H}_{2} \mathrm{O}, \mathrm{rt}, 5 \mathrm{~h}, 92 \%$} & \multicolumn{2}{|l|}{$80 \%$} & $31 \%$ \\
\hline
\end{tabular}


The Garner's aldehydes containing an Fmoc or Cbz protecting group (PG) could be synthesized from the corresponding methyl ester; however, lower yields were obtained for the DIBAL reduction, probably due to the DIBAL-mediated removal of the carbamates [32].

\section{Conclusion}

In conclusion, the first solution-phase automated synthesis of $\mathbf{4 a}$ (Boc protection) was demonstrated utilizing our originally developed automated synthesizer, ChemKonzert. The observed yields were comparable to those of the corresponding reported manual syntheses. In addition, $\mathbf{4 b}$ and $\mathbf{4 c}$ (Fmoc and $\mathrm{Cbz}$ protection) were also synthesized automatically according to the established procedure. Garner's aldehyde (4a) and its analogues are very important versatile intermediates. The automated synthesis of $\mathbf{4 a}$ can be applied to the synthesis of various useful compounds containing a vicinal amino alcohol moiety.

\section{Supporting Information}

\section{Supporting Information File 1}

Synthetic procedures and ${ }^{1} \mathrm{H}$ NMR spectral data of compounds $\mathbf{2 a}-\mathbf{c}, \mathbf{3 a}-\mathbf{c}$, and $\mathbf{4 a}-\mathbf{c}$.

[http://www.beilstein-journals.org/bjoc/content/ supplementary/1860-5397-13-13-S1.pdf]

\section{Acknowledgements}

We thank Mr. Kazuhiro Machida for assistance with the maintenance of ChemKonzert. We also thank Mr. Yoichiro Hirose for fruitful discussions.

\section{References}

1. Cork, D. G.; Sugawara, T., Eds. Laboratory Automation in the Chemical Industries; Marcel Dekker Inc.: New York, 2002. doi:10.1201/9780203908945

2. Li, J.; Ballmer, S. G.; Gillis, E. P.; Fujii, S.; Schmidt, M. J.; Palazzolo, A. M. E.; Lehmann, J. W.; Morehouse, G. F.; Burke, M. D. Science 2015, 347, 1221-1226. doi:10.1126/science.aaa5414

3. Adamo, A.; Beingessner, R. L.; Behnam, M.; Chen, J.; Jamison, T. F.; Jensen, K. F.; Monbaliu, J.-C. M.; Myerson, A. S.; Revalor, E. M.; Snead, D. R.; Stelzer, T.; Weeranoppanant, N.; Wong, S. Y.; Zhang, P. Science 2016, 352, 61-67. doi:10.1126/science.aaf1337

4. Seeberger, P. H.; Werz, D. B. Nat. Rev. Drug Discovery 2005, 4, 751-763. doi: $10.1038 / \mathrm{nrd} 1823$

5. Doi, T.; Fuse, S.; Miyamoto, S.; Nakai, K.; Sasuga, D.; Takahashi, T. Chem. - Asian J. 2006, 1, 370-383. doi:10.1002/asia.200600156

6. Fuse, S.; Ikebe, A.; Oosumi, K.; Karasawa, T.; Matsumura, K.; Izumikawa, M.; Johmoto, K.; Uekusa, H.; Shin-ya, K.; Doi, T.; Takahashi, T. Chem. - Eur. J. 2015, 21, 9454-9460. doi:10.1002/chem.201500703

7. Fuse, S.; Okada, K.; lijima, Y.; Munakata, A.; Machida, K.; Takahashi, T.; Takagi, M.; Shin-ya, K.; Doi, T. Org. Biomol. Chem. 2011, 9, 3825-3833. doi:10.1039/c0ob01169j
8. Tanaka, Y.; Fuse, S.; Tanaka, H.; Doi, T.; Takahashi, T. Org. Process Res. Dev. 2009, 13, 1111-1121. doi:10.1021/op9002455

9. Machida, K.; Hirose, Y.; Fuse, S.; Sugawara, T.; Takahashi, T. Chem. Pharm. Bull. 2010, 58, 87-93. doi:10.1248/cpb.58.87

10. Kher, S. S.; Penzo, M.; Fulle, S.; Finn, P. W.; Blackman, M. J.; Jirgensons, A. Bioorg. Med. Chem. Lett. 2014, 24, 4486-4489. doi:10.1016/j.bmcl.2014.07.086

11. Segade, Y.; Montaos, M. A.; Rodríguez, J.; Jiménez, C. Org. Lett. 2014, 16, 5820-5823. doi:10.1021/ol502958u

12. Vasudevan, N.; Kashinath, K.; Reddy, D. S. Org. Lett. 2014, 16, 6148-6151. doi:10.1021/ol503011g

13. Singh, P.; Manna, S. K.; Panda, G. Tetrahedron 2014, 70, 1363-1374. doi:10.1016/j.tet.2013.11.074

14. Takahata, H.; Banba, Y.; Ouchi, H.; Nemoto, H. Org. Lett. 2003, 5, 2527-2529. doi:10.1021/ol034886y

15. Sa-ei, K.; Montgomery, J. Tetrahedron 2009, 65, 6707-6711. doi:10.1016/j.tet.2009.05.029

16. Bhabak, K. P.; Proksch, D.; Redmer, S.; Arenz, C. Bioorg. Med. Chem. 2012, 20, 6154-6161. doi:10.1016/j.bmc.2012.08.035

17. Sudhakar, N.; Kumar, A. R.; Prabhakar, A.; Jagadeesh, B.; Rao, B. V. Tetrahedron Lett. 2005, 46, 325-327. doi:10.1016/j.tetlet.2004.11.035

18. Chen, J.; Chen, X.; Bois-Choussy, M.; Zhu, J. J. Am. Chem. Soc. 2006 128, 87-89. doi:10.1021/ja0571794

19. Passiniemi, M.; Koskinen, A. M. P. Beilstein J. Org. Chem. 2013, 9 , 2641-2659. doi:10.3762/bjoc.9.300

20. Karjalainen, O. K.; Koskinen, A. M. P. Tetrahedron 2014, 70, 2444-2448. doi:10.1016/j.tet.2014.02.020

21. Upadhyay, P. K.; Kumar, P. Synthesis 2010, 3063-3066. doi:10.1055/s-0030-1258185

22. Garner, P.; Park, J. M. Org. Synth. 1992, 70, 18-28. doi:10.15227/orgsyn.070.0018

23. Foss, F. W., Jr.; Snyder, A. H.; Davis, M. D.; Rouse, M.; Okusa, M. D.; Lynch, K. R.; Macdonald, T. L. Bioorg. Med. Chem. 2007, 15, 663-677. doi:10.1016/j.bmc.2006.10.060

24. Ocejo, M.; Vicario, J. L.; Badía, D.; Carrillo, L.; Reyes, E. Synlett 2005, 2110-2112. doi:10.1055/s-2005-871947

25. Dondoni, A.; Perroni, D. Org. Synth. 2000, 77, 64-77. doi:10.15227/orgsyn.077.0064

26. Jurczak, J.; Gryko, D.; Kobrzycka, E.; Gruza, H.; Prokopowicz, P. Tetrahedron 1998, 54, 6051-6064. doi:10.1016/S0040-4020(98)00299-3

27. Roush, W. R.; Hunt, J. A. J. Org. Chem. 1995, 60, 798-806. doi:10.1021/jo00109a008

28. Trajkovic, M.; Ferjancic, Z.; Saicic, R. N. Tetrahedron: Asymmetry 2012, 23, 602-604. doi:10.1016/j.tetasy.2012.03.019

29. Hoffman, T. J.; Kolleth, A.; Rigby, J. H.; Arseniyadis, S.; Cossy, J. Org. Lett. 2010, 12, 3348-3351. doi:10.1021/ol101145t

30. Cortes-Clerget, M.; Gager, O.; Monteil, M.; Pirat, J.-L.; Migianu-Griffoni, E.; Deschamp, J.; Lecouvey, M. Adv. Synth. Catal. 2016, 358, 34-40. doi:10.1002/adsc.201500794

31. Clemens, A. J. L.; Burke, S. D. J. Org. Chem. 2012, 77, 2983-2985. doi:10.1021/jo300025t

32. Rush, J.; Bertozzi, C. R. Org. Lett. 2006, 8, 131-134. doi:10.1021/ol052623t

33. Jiang, S.; Li, P.; Lai, C. C.; Kelley, J. A.; Roller, P. P. J. Org. Chem. 2006, 71, 7307-7314. doi:10.1021/jo061037q

34. Martin, N. I.; Woodward, J. J.; Winter, M. B.; Marletta, M. A. Bioorg. Med. Chem. Lett. 2009, 19, 1758-1762. doi:10.1016/j.bmcl.2009.01.076 
35. Lingamurthy, M.; Jagadeesh, Y.; Ramakrishna, K.; Rao, B. V.

J. Org. Chem. 2016, 81, 1367-1377. doi:10.1021/acs.joc.5b02275

\section{License and Terms}

This is an Open Access article under the terms of the Creative Commons Attribution License

(http://creativecommons.org/licenses/by/4.0), which permits unrestricted use, distribution, and reproduction in any medium, provided the original work is properly cited.

The license is subject to the Beilstein Journal of Organic Chemistry terms and conditions:

(http://www.beilstein-journals.org/bjoc)

The definitive version of this article is the electronic one which can be found at:

doi:10.3762/bjoc.13.13 